\title{
Terra e água na reforma agrária do semi-árido norteriograndense ${ }^{1}$
}

Márcio R. Francelino² ${ }^{2}$ Elpídio I. Fernandes Filho ${ }^{3} \&$ Mauro Resende ${ }^{4}$

1 Parte da Dissertação do primeiro autor, que teve apoio da WWF do Brasil

2 UFV. CP 277, CEP 36570-000, Viçosa, MG. Fone: (31) 3899-1040. E-mail: france@solos.ufv.br (Foto)

3 UFV. CEP 36570-000, Viçosa, MG. Fone: (31) 3899-1040. E-mail: elpidio@solos.ufv.br

${ }^{4}$ NEPUT. Vila Giannet, Casa 13, Viçosa, MG. Fone: (31) 3899-2894. E-mail: neput@solos.ufv.br

Protocolo 093 - 26/6/2001

\begin{abstract}
Resumo: Este trabalho teve como meta principal avaliar os recursos hídricos em dez projetos de assentamento na região Oeste do estado do Rio Grande do Norte. Para isto, analisaram-se parâmetros físico-químicos das águas e se determinou a relação dos assentados com os recursos hídricos de suas respectivas áreas. Os resultados analíticos demonstraram que a qualidade das águas de todos os assentamentos estudados, apresentou restrição para o seu uso na irrigação, enquanto em Cordão de Sombra e Esperança, a água apresentou teores de cloreto acima do máximo recomendado para o consumo humano. Deve-se considerar a limitação das reservas hídricas ao se diagnosticar a sustentabilidade dos agrossistemas na região, pois a água é o fator determinante para o sucesso ou fracasso do empreendimento de reforma agrária nas condições de semi-aridez.
\end{abstract}

Palavras-chave: caatinga, sustentabilidade, Rio Grande do Norte, assentamentos

\section{Land and water in agrarian reform of semiarid region of Rio Grande do Norte State - Brazil}

\begin{abstract}
This study aimed to evaluate the water resources in ten settlement projects in western part of the Rio Grande do Norte State. The chemical-physical parameters of waters were analyzed and the relationship between the settler and the water resources in their respective areas were determined. The results obtained showed that the waters of all settlements presented restriction for their use in irrigation, whe reas in settlements of Cordão de Sombra and Esperança the water presented chloride contents above the maximum recommended for human consumption. In diagnosing the sustainability of the agrosystems in the region, one should consider the limitation of the water reserves, since the water is a determinant factor for the success or failure of the agrarian reform under semiarid conditions.
\end{abstract}

Key words: caatinga, Rio Grande do Norte, sustainability, settlement projects

\section{INTRODUÇÃO}

O semi-árido nordestino ocupa uma área de aproximadamente $700.000 \mathrm{~km}^{2}$, com população de 23 milhões de pessoas, em que, segundo Ab’Saber (1999): “... segue tendo muito mais gente que as relações de produção ali imperantes podem suportar”.

Esse adensamento humano, atípico para uma região semiárida, acentua a debilidade do seu ecossistema. A locação de projetos de assentamento (PA) no seu perímetro, deveria considerar esta fragilidade, exigindo-se maiores preocupações com a escassez de recursos naturais que garantam sobrevivência digna aos trabalhadores. $\mathrm{O}$ acesso ao seu principal desvio ecológico, a água, deveria nortear os planejamentos das instituições responsáveis pela implementação da política agrária, ou seja, não somente democratizar o acesso à terra mas, também, à água.
Os assentamentos localizados na região oeste do estado do Rio Grande do Norte dependem, basicamente, da água subterrânea da bacia Potiguar, que possui uma área de $23.000 \mathrm{~km}^{2}$, com volume de $230 \mathrm{~km}^{3}$, constituída de dois aqüíferos: um localizado no calcário da Formação Jandaíra, e o outro, do tipo poroso, no Arenito Açu, que apresenta limitada área de recarga (Maia Neto, 1998). Para se ter acesso à água deste aqüífero, que é de melhor qualidade, muitas vezes é necessário perfurar cerca de $1.000 \mathrm{~m}$, elevando o custo do poço para valores próximos de U\$ 450.000,00.

Diversos parâmetros determinam a qualidade da água para seus múltiplos usos. Para o consumo humano, além dos aspectos biológicos são importantes as suas características físico-químicas. Em relação à utilização na agricultura, determinam-se outros parâmetros, associando-os a fatores 
Tabela 1. Caracterização socioespacial dos assentamentos estudados

\begin{tabular}{|c|c|c|c|c|c|}
\hline \multirow{2}{*}{ Assentamento } & \multirow{2}{*}{ Município } & \multirow{2}{*}{ Ano Criação } & \multirow{2}{*}{$\mathrm{N}^{\circ}$ de Família } & Área & Área/Família \\
\hline & & & & \multicolumn{2}{|c|}{ ha } \\
\hline Aurora da Serra & Apodi & 97 & 58 & $1.435,39$ & 25 \\
\hline Cabelo de Negro & Mossoró & 95 & 96 & $2.821,72$ & 29 \\
\hline Canto Comprido & Carnaubais & 95 & 127 & $3.917,79$ & 31 \\
\hline Cordão de Sombra & Mossoró & 96 & 117 & $3.997,66$ & 34 \\
\hline Esperança & Upanema & 96 & 76 & $2.300,73$ & 30 \\
\hline Hipólito & Mossoró & 87 & 137 & $4.840,80$ & 35 \\
\hline Lagoa Vermelha & Upanema & 95 & 34 & $1.194,25$ & 35 \\
\hline Mulunguzinho & Mossoró & 92 & 112 & $4.000,00$ & 36 \\
\hline Recreio & Mossoró & 96 & 73 & $2.047,31$ & 28 \\
\hline Soledade & Apodi & 89 & 34 & 999,51 & 29 \\
\hline Total & & & 864 & $27.555,16$ & 32 \\
\hline
\end{tabular}

como tipo de solo, sistema de irrigação e drenagem, tolerância da cultura e condições climáticas, a fim de se classificar sua adequação e identificar suas restrições (Holanda \& Amorim, 1997). Esses parâmetros são particularmente importantes para regiões semi-áridas.

Este trabalho teve como objetivo avaliar a situação dos recursos hídricos em dez projetos de assentamento na região Oeste do estado do Rio Grande do Norte e sua importância para a sustentabilidade dos projetos de reforma agrária na região.

\section{MATERIAL E MÉTODOS}

Selecionaram-se dez assentamentos na região oeste do estado do Rio Grande do Norte (Tabela 1), sete dos quais possuem acesso ao manancial subterrâneo (poços profundos) com fornecimento regular de água, e os demais não possuem fonte própria deste recurso.

Em relação à quantidade mínima diária de água recomendada para o consumo humano, consideraram-se os dados citados por Suassuna (1999a) que apresentam uma média de $126 \mathrm{~L} \mathrm{~d}^{-1}$ pessoa. Para o consumo animal, foi utilizado somente o valor para caprinos, visto ser este o principal rebanho encontrado nos projetos de assentamento, que se situa entre 10 e $20 \mathrm{~L} \mathrm{~d}^{-1}$ animal (Suassuna, 1999a).

Para o cálculo da demanda usual, consideraram-se os seguintes fatores:

Consumo humano $=$ população $\times 0,126 \mathrm{~m}^{3} \mathrm{~d}^{-1}$

Consumo animal $=\mathrm{n}^{\circ}$ de famílias $\times 4 \times 0,01 \mathrm{~m}^{3} \mathrm{~d}^{-1}$

Consumo irrigação = área irrigada (ha) $\times 60 \mathrm{~m}^{3} \mathrm{~d}^{-1}$

Demanda usual $\left(\mathrm{m}^{3} \mathrm{~d}^{-1}\right)=$ consumo humano + consumo animal + consumo irrigação

O fator multiplicativo do consumo animal, no valor de 4, está relacionado com o número médio de animais que compõem o rebanho, conforme levantamento do autor. No caso do valor de $60 \mathrm{~m}^{3} \mathrm{~d}^{-1}$ para irrigação, foi considerada uma lâmina média diária de $6 \mathrm{~mm}$.

Foram coletadas amostras das águas de sete assentamentos no mês de setembro de 1999. As leituras de $\mathrm{pH}$ e condutividade elétrica $\left(\mathrm{CE} \mathrm{a} 25^{\circ} \mathrm{C}\right)$ foram realizadas em tempo inferior a $16 \mathrm{~h}$, após a amostragem no ponto de coleta. A caracterização físicoquímica foi determinada através da leitura de $\mathrm{Ca}^{2+}, \mathrm{Mg}^{2+}, \mathrm{Na}^{+}$, $\mathrm{K}^{+}, \mathrm{CO}_{3}{ }^{2-}, \mathrm{Cl}^{-}$e $\mathrm{HCO}_{3}{ }^{2-}$, segundo Golterman (1970) e os sulfatos foram estimados pela diferença entre cátions e ânions. Para avaliar a qualidade da água para irrigação quanto aos efeitos no solo, estimou-se o valor da Relação de Adsorção de Sódio corrigida $\left(\right.$ RAS $\left.^{\circ}\right)$, conforme Ayers \& Westcot (1991).

$$
\operatorname{RAS}^{\circ}=\frac{\mathrm{Na}}{\sqrt{\frac{\left(\mathrm{Ca}^{\circ}+\mathrm{Mg}\right)}{2}}}
$$

Adotou-se, posteriormente, o sistema de classificação quanto ao risco de salinidade da University of California Committee of Consultants, citado por Holanda \& Amorim (1997).

Estimou-se, ainda, o teor de carbonato de sódio residual (CSR) pela diferença entre o somatório dos carbonatos e bicarbonatos e o somatório do cálcio mais magnésio.

$$
\mathrm{CSR}=\left(\mathrm{CO}_{3}{ }^{2-}+\mathrm{HCO}_{3}^{-}\right)-\left(\mathrm{Ca}^{2+}+\mathrm{Mg}^{2+}\right)
$$

Em relação ao consumo humano, foram considerados os limites estipulados pela Organização Mundial da Saúde (OMS) (Tabela 2).

Tabela 2. Limites máximos de diversos parâmetros utilizados na avaliação da qualidade da água para o consumo humano

\begin{tabular}{lcc}
\multicolumn{1}{c}{ Parâmetro } & Unidade & Limite \\
\hline $\mathrm{pH}$ & & $5,0-9,0$ \\
Condutividade elétrica & $\mathrm{dS} \mathrm{m}^{-1}$ & $0,4^{1}$ \\
Cloretos & $\mathrm{mg} \mathrm{L}^{-1}$ & 250 \\
Sulfatos & $\mathrm{mg} \mathrm{L}^{-1}$ & 250 \\
Cálcio & $\mathrm{mg} \mathrm{L}^{-1}$ & 100 \\
Magnésio & $\mathrm{mg} \mathrm{L}^{-1}$ & 50 \\
Sódio & $\mathrm{mg} \mathrm{L}^{-1}$ & 150 \\
Potássio & $\mathrm{mg} \mathrm{L}^{-1}$ & 12 \\
\hline
\end{tabular}

${ }^{1}$ Recomendado

Fonte: Oliveira (1999)

\section{RESULTADOS E DISCUSSÃO}

Devido às dificuldades de armazenamento de água na superfície na área do estudo, em conseqüência, além da baixa precipitação pluviométrica, da presença do substrato de calcário, cujas rochas possuem fraturas e superfície de descontinuidade primária, com aberturas alargadas por processos de dissolução pela água (sumidouros), o acesso a este recurso se dá basicamente sob a forma de poços tubulares. Esses poços 
apresentam grande variabilidade na qualidade da água e na sua vazão, em virtude da existência de dois mananciais distintos na região: um de natureza cárstico-fissural, no calcário Jandaíra, que internamente é ainda influenciado pelo grau de solubilização deste substrato, e o outro, no Arenito Açu, manancial que apresenta qualidade de água superior e mais uniforme.

Das dez áreas estudadas, Aurora da Serra, Cabelo de Negro e Canto Comprido, não possuem fontes próprias de abastecimento de água, enquanto Cordão Sombra, Esperança e Lagoa Vermelha, não apresentam água em quantidade e/ou qualidade satisfatória, o que refletirá no seu tipo de uso

Tabela 3. Uso da água em sete assentamentos da região oeste do Rio Grande do Norte e localização do lençol subterrâneo

\begin{tabular}{|c|c|c|c|c|}
\hline \multirow{2}{*}{$\begin{array}{c}\text { Projeto de } \\
\text { Assetamento }\end{array}$} & \multicolumn{3}{|c|}{ Uso } & \multirow{2}{*}{ Localização } \\
\hline & Doméstico & Animal & Irrigação & \\
\hline Cordão de Sombra & $\mathrm{X}$ & $\mathrm{X}$ & & Calcário ${ }^{1}$ \\
\hline Hipólito & $\mathrm{X}$ & $\mathrm{x}$ & $\mathrm{x}$ & Arenito $^{2}$ \\
\hline Recreio & $\mathrm{x}$ & $\mathrm{x}$ & $\mathrm{x}$ & Calcário \\
\hline Soledade & $\mathrm{x}$ & $\mathrm{x}$ & $\mathrm{X}$ & Arenito \\
\hline Esperança & $\mathrm{x}$ & & & Arenito \\
\hline Lagoa Vermelha & $\mathrm{x}$ & $\mathrm{x}$ & & Arenito \\
\hline Mulunguzinho & $\mathrm{x}$ & $\mathrm{x}$ & $\mathrm{X}$ & Arenito \\
\hline
\end{tabular}

${ }^{1}$ Calcário Formação Jandaíra

${ }^{2}$ Arenito Açu

\section{(Tabela 3).}

\section{Qualidade}

Para o consumo humano, os resultados das análises das águas (Tabela 4), demonstram que, considerando-se apenas parâmetros físico-químicos, somente os assentamentos Mulunguzinho e Soledade não apresentaram nenhuma restrição. A água de Hipólito também pode ser incluída, pois seu único fator restritivo foi a condutividade elétrica que, em si, não apresenta qualquer problema para a saúde do consumidor, dado o seu caráter não-específico. Seu valor máximo é apenas um limite recomendado, não sendo encontrada nenhuma associação com outros componentes que comprometesse sua qualidade. Cordão de Sombra e Esperança apresentaram teores de cloreto acima do máximo recomendado para o consumo humano, segundo a Organização Mundial de Saúde.

Os três poços tubulares mais profundos apresentaram as maiores vazões e água de melhor qualidade, devido ao fato de explorarem o aqüífero do Arenito Açu. A menor profundidade do poço de Soledade se deve à sua localização na faixa oeste da Chapada do Apodi, perto da sua borda, onde o calcário apresenta menor espessura (na região próximo a Mossoró, ele alcança cerca de $600 \mathrm{~m}$ (Ernesto Sobrinho, 1981)).

A grande variabilidade nas características físico-químicas da água com a profundidade, pode ser decorrente do grau de solubilidade do calcário da Formação Jandaíra, em que, quanto mais solúvel o calcário, mais baixa a qualidade da água, como foi observado no poço do PA Cordão de Sombra, que apresentou restrições para quase todos os parâmetros.

Como se trata de água de lençóis subterrâneos, seu comportamento químico mostra variação temporal baixa, diferente das fontes superficiais, que apresentam maior dinâmica.

Em relação ao seu uso na agricultura e se considerando que apenas quatro projetos possuem sistemas de irrigação localizada, calcularam-se alguns parâmetros, a fim de se avaliar sua utilização nessa atividade (Tabela 5). Os demais assentamentos não apresentaram oferta de água suficiente para instalação de projetos de irrigação (Tabela 6).

Tabela 6. Disponibilidade e demanda usual dos recursos hídricos de sete projetos de assentamento do Rio Grande do Norte

\begin{tabular}{lcrc}
\hline \multirow{2}{*}{$\begin{array}{c}\text { Projeto de } \\
\text { Assentamento }\end{array}$} & $\begin{array}{c}\text { Disponibilidade } \\
\text { Instalada }\end{array}$ & $\begin{array}{c}\text { Demanda } \\
\text { Usual }\end{array}$ & $\begin{array}{c}\text { Disponibilidade } \\
\text { Usual }^{1} \\
\mathrm{~h} \mathrm{dia}^{-1}\end{array}$ \\
\cline { 2 - 3 } Cordão de Sombra & \multicolumn{2}{c}{$\mathrm{m}^{3} \mathrm{dia}^{-1}$} & \\
Hipólito & 16,8 & 66,00 & - \\
Recreio & $1.368,0$ & 977,27 & 17 \\
Soledade & $768,0^{2}$ & 281,17 & 9 \\
Esperança & $1.920,0$ & $1.280,30$ & 16 \\
Lagoa Vermelha & 24,0 & 42,86 & - \\
Mulunguzinho & 69,6 & 34,18 & 12 \\
\hline
\end{tabular}

${ }^{1}$ Refere-se à quantidade de horas necessárias de bomba ligada para cobrir a demanda ${ }^{2}$ Somatória da vazão dos quatro poços tubulares

Tabela 4. Análises físico-químicas das águas de sete assentamentos do Rio Grande do Norte*

\begin{tabular}{|c|c|c|c|c|c|c|c|c|c|c|}
\hline \multirow{2}{*}{$\begin{array}{c}\text { Projeto de } \\
\text { Assentamento }\end{array}$} & \multirow{2}{*}{$\begin{array}{c}\text { Prof. } \\
\text { m }\end{array}$} & \multirow{2}{*}{$\begin{array}{c}\mathrm{Q} \\
\mathrm{m}^{3} \mathrm{~h}^{-1}\end{array}$} & \multirow[t]{2}{*}{$\mathrm{pH}$} & \multirow{2}{*}{$\begin{array}{c}\mathrm{CE} \\
\mathrm{dS} \mathrm{m}{ }^{-1}\end{array}$} & $\mathrm{Na}^{+}$ & $\mathrm{K}^{+}$ & $\mathrm{Ca}^{2+}$ & $\mathrm{Mg}^{2+}$ & $\mathrm{Cl}^{-}$ & $\mathrm{SO}_{4}{ }^{2-}$ \\
\hline & & & & & \multicolumn{6}{|c|}{$\mathrm{mmol}_{\mathrm{c}} \mathrm{l}^{1}$} \\
\hline Cordão de Sombra & 200 & 0,7 & 7,3 & 2,85 & 7,87 & 0,44 & 3,94 & 5,55 & 10,80 & 4,09 \\
\hline Hipólito & 690 & 57,0 & 8,1 & $\mathbf{0 , 8 1}$ & 5,02 & 0,18 & 0,55 & 0,85 & 3,20 & 0,30 \\
\hline Recreio & 164 & 8,0 & 7,3 & 1,30 & 3,00 & 0,05 & 2,65 & 1,45 & 4,50 & 0,27 \\
\hline Soledade & 272 & 80,0 & 7,0 & 0,11 & 0,21 & 0,11 & 0,45 & 0,01 & 0,60 & 0,00 \\
\hline Esperança & 36 & 1,0 & 6,1 & 1,10 & 4,81 & 0,49 & 1,05 & 0,80 & 7,20 & 0,45 \\
\hline Lagoa Vermelha & 66 & 2,9 & 6,3 & 0,38 & 1,39 & 0,49 & 0,60 & 0,05 & 2,50 & 0,19 \\
\hline Mulunguzinho & 777 & 18,0 & 7,9 & 0,76 & 4,57 & 0,15 & 0,60 & 0,05 & 1,60 & 0,31 \\
\hline
\end{tabular}

"Valores em negrito - com restrição para consumo humano

Tabela 5. Qualidade da água de quatro assentamentos do Rio Grande do Norte para uso na irrigação

\begin{tabular}{|c|c|c|c|c|c|c|c|}
\hline \multirow{2}{*}{$\begin{array}{c}\text { Projeto de } \\
\text { Assentamento }\end{array}$} & \multirow{2}{*}{$\begin{array}{c}\text { RAS }{ }^{1} \\
\left(\operatorname{mmol}_{\mathrm{c}} \mathrm{L}^{-1}\right)^{1 / 2}\end{array}$} & $\mathrm{CO}_{3}{ }^{2-}$ & $\mathrm{HCO}_{3}^{-}$ & \multirow{2}{*}{$\mathrm{Ca} / \mathrm{Mg}$} & \multirow{2}{*}{$\begin{array}{c}\mathrm{CSR}^{2} \\
\mathrm{mmol}_{\mathrm{c}} \mathrm{L}\end{array}$} & \multicolumn{2}{|c|}{ Risco de $\mathrm{Uso}^{3}$} \\
\hline & & \multicolumn{2}{|c|}{$\mathrm{mmol}_{\mathrm{c}} \mathrm{L}^{-1}$} & & & Salinidade & Permeabilidade \\
\hline Hipólito & 5,08 & 0 & 3,9 & 0,6 & 2,5 & Moderado & Moderado \\
\hline Mulunguzinho & 7,78 & 0 & 3,5 & 12,0 & 2,8 & Moderado & Moderado \\
\hline Recreio & 2,60 & 0 & 6,2 & 1,8 & 2,1 & Moderado & Nenhuma \\
\hline Soledade & 0,29 & 0 & 1,0 & 45,0 & 0,5 & Nenhuma & Severo \\
\hline
\end{tabular}

${ }^{1}$ Relação de adsorção de sódio corrigida

${ }^{2}$ Carbonato de Sódio Residual $=\left(\mathrm{CO}_{3}^{2-}+\mathrm{HCO}_{3}^{-}\right)-\left(\mathrm{Ca}^{2+}+\mathrm{Mg}^{2+}\right)$

${ }_{3}^{3}$ Classificação de salinidade segundo o University of California Committee of Consultants (UCCC), R - Restrição de uso 
Todas as águas apresentaram restrição de uso na irrigação. Com relação ao risco de salinização, segundo a classificação da UCCC, apenas Soledade não apresentou problema, enquanto as demais foram classificadas como de moderado risco. Quanto ao risco de sodicidade, ocorreu variação de baixo (Recreio) a alto (Soledade).

Os altos teores de bicarbonato encontrados favorecem a precipitação do Ca em forma de carbonatos (Holanda \& Amorim, 1997) que, segundo Maia et al. (1998) facilita a obstrução dos emissores na irrigação pressurizada.

A relação de $\mathrm{Ca} / \mathrm{Mg}<1,00$, encontrada na água de Hipólito, poderia ocasionar a formação de interação negativa entre esses nutrientes no solo, porém isso é amenizado pelo alto teor de $\mathrm{Ca}^{2+}$ encontrado no solo deste assentamento. Salienta-se que dos assentamentos com projetos de irrigação, apenas Recreio explora o lençol subterrâneo do calcário.

Os baixos valores de CSR encontrados se devem ao fato das águas apresentarem elevados teores, tanto de $\mathrm{HCO}_{3}{ }^{-}$como

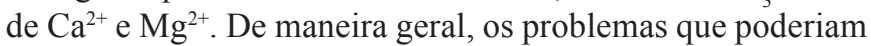
surgir com o uso dessas águas, são amortizados devido à utilização do sistema de irrigação localizada; no entanto, é necessário monitoramento constante desses solos, principalmente daqueles que apresentam solos com altos teores de argila de alta atividade (2:1) comuns na Chapada do Apodi, região onde está localizada a maioria dos assentamentos estudados, ressaltando que a principal cultura explorada pelos assentados é o melão, com uso intenso de insumos externos. A prática desta monocultura poderá, ao longo dos anos, trazer danos de difícil (e onerosa) correção.

\section{Quantidade}

Os dados mais recentes sobre a disponibilidade instalada na bacia Potiguar, datam de 1972. Nesse intervalo de 29 anos, a região ganhou grande impulso no tamanho da sua área irrigada, com abertura de vários poços, além do aumento no consumo das cidades. Portanto, as informações disponibilizadas não retratam a real condição dos recursos hídricos dessa bacia. $\mathrm{O}$ que se sabe é que, nas condições atuais de exploração dos aqüíferos, são necessários constantes ajustamentos das profundidades das bombas submersas dos poços, em razão do rebaixamento progressivo do nível dinâmico do lençol, estimado na ordem de $5 \mathrm{~m}^{-1}$ ano $^{-1}$ (Brasil, 1998a). Considerando-se a espessura do Arenito Açu em torno de $300 \mathrm{~m}$ e se mantendo esse nível de rebaixamento, tendo como marco zero o ano corrente (2000) pode-se, grosseiramente, calcular sua reserva para cerca de 60 anos. Esse curto intervalo condiciona qualquer premissa de sustentabilidade dos agrossistemas instalados na região, com base na redução do desvio "água", a questionamentos. Também tem sido relatada presença de gases e óleo nas águas de alguns dos poços (Brasil, 1998b).

Na região há duas empresas agropecuárias: a MAISA e a FRUNORTE que, juntas, irrigam cerca de 5.200 ha. O volume de água gasto, considerando-se uma lâmina diária de $6 \mathrm{~mm}$, daria para fornecer água para quase 2.500 .000 pessoas, para um consumo de $126 \mathrm{~L} \mathrm{~d}^{-1}$ pessoa.

Em relação aos assentamentos estudados, Cordão de Sombra, Esperança e Mulunguzinho só conseguem suprir 25, 56 e $25 \%$, respectivamente, das suas demandas. Para as demais áreas, são necessários longos períodos com a bomba ligada (Tabela 6), acarretando maiores custos energéticos.

\section{Alternativas}

Os assentamentos de Esperança e Lagoa Vermelha, localizados na região do Arenito Açu, não estão utilizando devidamente o seu provável potencial hídrico, já que, segundo informações colhidas na região, com cerca de $100 \mathrm{~m}$ de profundidade se alcançaria o aqüífero daquele substrato.

Em relação às condições climáticas e se analisando somente os dados sobre as normais pluviométricas da região, que apresentam precipitação média em torno de $765 \mathrm{~mm} \mathrm{ano}^{-1}$ (Figura 1A), fica difícil entender a sua real situação de carência hídrica, ou seja, o problema não é a quantidade média de chuvas e, sim, a sua grande variabilidade espaço-temporal, alternando-se anos muito secos, como 1993, que apresentou média de $185 \mathrm{~mm}$, e muito úmidos, como 1994, com precipitação de $1.036 \mathrm{~mm}$ (Figura 1B).

A.

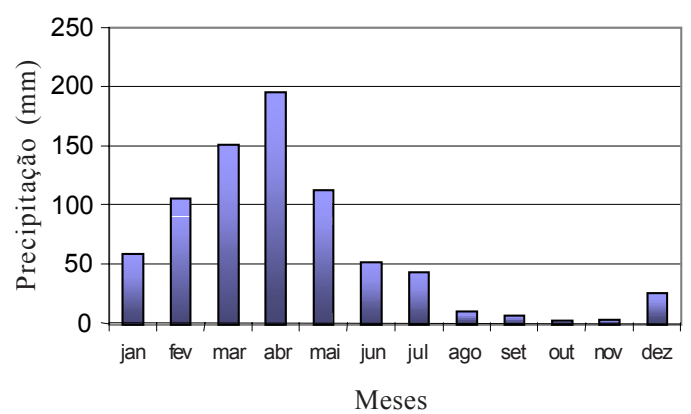

Fonte: Brasil (1992)

B.

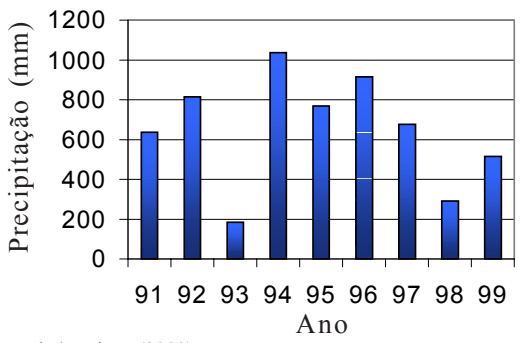

Fonte: http://www.esam.br/serviços (2000)

Figura 1. Variações pluviométricas de Mossoró, RN, referentes à normal do período de 1961 a 1990 (A) e médias anuais do período de 1991 a 1999 (B)

Algumas medidas mitigadoras estão sendo tomadas pelo Poder Público. O abastecimento da cidade de Mossoró, que era realizado por 18 poços, foi acrescido da água da Represa Armando Ribeiro Gonçalves, por meio de uma adutora de $65,7 \mathrm{~km}$, que transporta $365 \mathrm{~L} \mathrm{seg}^{-1}$ (Brasil, 1998b). Não se considerando a demanda para uso consuntivo, mas apenas o consumo direto, que corresponde a $46 \mathrm{~m}^{3} \mathrm{ano}^{-1} \mathrm{hab}^{-1}$ (Suassuna, 1999b) essa quantidade é suficiente para cobrir as necessidades da população mossoroense. A construção da barragem de Santa Cruz no Rio Apodi-Mossoró, cuja obra já foi iniciada e, caso a transposição do Rio São Francisco realmente se concretize, serão outras alternativas que poderão melhorar muito o abastecimento hídrico da região, favorecendo principalmente a expansão da agricultura irrigada.

Em relação às comunidades rurais, incluindo-se alguns assentamentos, estão sendo instalados vários dessalinizadores. São equipamentos que processam a retirada dos sais da água 
por meio de membranas (osmose reversa) transformando água com altos teores de sais praticamente em água destilada, com o custo do $\mathrm{m}^{3}$ estimado em torno de U\$ 0,80 (Suassuna, 1999b).

Uma alternativa interessante é a que foi implantada no assentamento de Canto Comprido, onde se construíram cisternas de placa para captação de águas pluviais, com capacidade de armazenar $12.000 \mathrm{~L}$ cada uma; quando bem manejadas, elas podem garantir o abastecimento de água potável para uma família de cinco pessoas (considerando-se um consumo de $10 \mathrm{~L}_{\text {pessoa }}{ }^{-1} \mathrm{~d}^{-1}$ ) durante oito meses, justamente no período da estiagem. A sua construção é simples e o custo relativamente baixo, em torno de U\$ 235 cada uma, desde que seja construída pelo próprio agricultor, em mutirão.

Não há muitas opções de geração de renda nessas áreas, principalmente naquelas com problema de abastecimento de água. A sua contabilização é difícil, devido à informalidade das atividades extra-assentamentos e das não-agrícolas; nota-se, entretanto, certa concentração em três atividades: na pecuária extensiva, no extrativismo florestal e na fruticultura irrigada (Tabela 7), que utiliza modernos sistemas de irrigação localizada e é calcada nas cucurbitáceas (melão e melancia).

Tabela 7. Principais atividades econômicas dos assentamentos Projeto de Assentamento Principal Atividade Econômica

\begin{tabular}{ll}
\hline Aurora da Serra & Pecuária extensiva \\
Cabelo de Negro & Extrativismo florestal \\
Canto Comprido & Extrativismo florestal \\
Cordão de Sombra & Pecuária extensiva/extrativismo florestal \\
Esperança & Pecuária extensiva \\
Hipólito & Fruticultura irrigada \\
Lagoa Vermelha & Pecuária extensiva \\
Mulunguzinho & Fruticultura irrigada \\
Recreio & Pecuária extensiva \\
Soledade & Fruticultura irrigada \\
\hline
\end{tabular}

O fator produtivo preponderante é a água, cuja presença constitui, até o momento, o divisor entre o melhor ou o pior padrão de qualidade de vida, observado na Tabela 8 , em que se considera a renda média mensal por família de três assentamentos, em que o primeiro, Cabelo de Negro, não possui água e tem como principal atividade econômica o extrativismo florestal, enquanto os dois seguintes, Hipólito e Soledade, produzem melão para exportação. Os valores foram baseados nos volumes totais comercializados e o seu preço médio deduzido dos custos de produção.

Tabela 8. Renda média mensal das principais atividades econômicas de três assentamentos do Rio Grande do Norte

Projeto de Principal Atividade $\mathrm{N}^{\circ}$ de Renda/família/mês

\begin{tabular}{lccc}
\multicolumn{1}{c}{ Assentamento } & Econômica & Famílias & (R\$) \\
\hline Cabelo de Negro Extrativismo florestal & 96 & 36,00 \\
Hipólito & Fruticultura irrigada & 44 & 177,00 \\
Soledade & Fruticultura irrigada & 33 & 216,00 \\
\hline
\end{tabular}

\section{CONCLUSÕES}

1. Dos 7 assentamentos que possuem fonte própria de água, apenas 4 conseguem cobrir suas demandas, porém a qualidade das águas de todos eles apresentou algum tipo de restrição para uso na irrigação, enquanto para o consumo humano apenas Mulunguzinho e Soledade não indicaram limitações químicas. Nos assentamentos Cordão de Sombra e Esperança, a água mostrou teores de cloreto acima do máximo recomendado para o consumo humano, sendo necessário o uso de dessalinizadores nessas áreas.

2. A presença de oferta de água com qualidade e quantidade satisfatórias que permitam a instalação de projetos de irrigação, alavanca consideravelmente o desenvolvimento dos assentamentos, com influência direta no aumento da renda média das famílias.

3. Deve-se considerar a limitação das reservas hídricas ao se diagnosticar a sustentabilidade dos agrossistemas na região, mesmo que existam alternativas para, caso não se resolva, pelo menos amenizar a carência hídrica da região, pois a água é o fator determinante para o sucesso ou fracasso do empreendimento de reforma agrária, nas condições de semi-aridez.

\section{LITERATURA CITADA}

Ab'Saber, A.N. Sertões e sertanejos: uma geografia humana sofrida. Estudos Avançados, São Paulo, v.13, n.36, p.33-47, 1999.

Ayers, R.S.; Westcot, D.W. A qualidade da água na agricultura. Campina Grande: UFPB. 1991.218p.

Brasil. Normais climatológicas. 1.ed. Brasília: INMET, 1992. 568p.

Brasil. Plano operativo anual do Rio Grande do Norte: Programa Proágua Semi-árido. Brasília: s.d. 1998a. 215p.

Brasil. Instrução normativa n 1/98. Brasília: MMA/IBAMA. 1998b. 15p.

Costa, W.D.; Costa, W.D. Disponibilidades hídricas subterrâneas na região nordeste do Brasil. São Paulo: Ciência \& Tecnologia, 1997.

Ernesto Sobrinho, F. Levantamento de reconhecimento semidetalhado e interpretação para uso dos solos da Serra do Mel, RN. 1.ed. Mossoró: Coleções Mossoroense, 1981. 150p.

ESAM - Escola Superior de Agricultura de Mossoró. Dados climatológicos. http://www.esam.br. 15 Jan. 2000.

Golterman, H.L. Methods of chemical analysis of fresh water. Oxford: Blackwell Scientific Publications, 1970. 465p.

Holanda, J.S.; Amorim, J.R.A. Qualidade da água para irrigação In: Gheyi, H.R.; Queiroz, J.E.; Medeiros, J.F.(ed.). Manejo e controle da salinidade na agricultura irrigada. Campina Grande: UFPB, 1997. Cap. 5, p.137-165.

Maia, C.E.; Morais, E.R.C.; Oliveira, M. Qualidade de água para fertirrigação por gotejamento. II Região do Baixo-Açu, RN. Engenharia na Agricultura, Viçosa, v.6, n.1, p.12-26, 1997.

Maia Neto, R.F. Água para o desenvolvimento sustentável. São Paulo: Ensaios e Dissertações, 1998.

Oliveira, S. Decreto-Lei no 74/90. http://www.epa.pt. 17 Dez. 1999.

Suassuna, J. Água no planeta: origem, quantidades globais e consumo potencial. http://www.fundaj.gov.br. Fev. 1999a.

Suassuna, J. Água potável no semi-árido: escassez anunciada. http://www.fundaj.gov.br. Fev.1999b. 